\title{
O PROGRAMA INSTITUCIONAL DE BOLSA DE INICIAÇÃO À DOCÊNCIA (PIBID) DO CURSO DE GEOGRAFIA/UFGD: LINGUAGENS, PRÁTICA E FORMAÇÃO DE PROFESSORES
}

\author{
INSTITUTIONAL PROGRAM OF SCHOLARSHIP FOR TEACHING PROCESS INTRODUCTION (PIBID) FROM \\ UFGD GEOGRAPHY DEPARTMENT: LANGUAGES, PRACTICE AND TEACHING FORMATION PROCESS
}

\author{
Silvana de Abreu ${ }^{1}$, Adáuto de Oliveira Souza ${ }^{1}$ \\ ${ }^{1}$ Universidade Federal da Grande Dourados (UFGD), Dourados, MS, Brasil
}

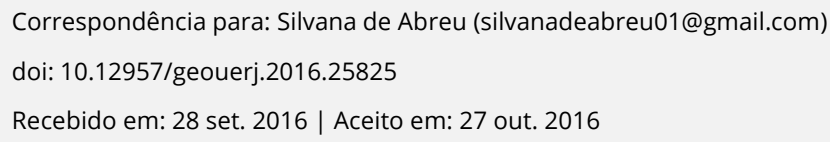

\section{RESUMO}

É objetivo deste trabalho, analisar o processo formativo dos professores de Geografia considerando políticas instaladas recentemente no Brasil, cujas proposições visam melhorar a prática do professor, o que significa atuar na sua formação e na formação do estudante, no Ensino Básico. Dessa forma, nos voltamos para a experiência promovida pelo Programa Institucional de Bolsas de Iniciação à Docência (PIBID), criado como política governamental para promover melhorias na formação de professores e também na educação básica. $O$ Programa concede bolsas para alunos das licenciaturas participantes, orientados por professores universitários que elaboram e coordenam o Projeto, bem como bolsas para professores-supervisores, nas escolas envolvidas, para dedicarem-se aos projetos, dos quais também são sujeitos. Os acadêmicos vivenciam as questões que envolvem a escola, a formação (fora da sala de aula) e o planejamento escolar. Como desdobramento do PIBID/Geografia/UFGD, o ganho para a formação do futuro professor comparece em experiências registradas evidenciando a incorporação de diferentes linguagens e práticas formadoras que buscam superar o uso do livro didático sem, contudo, desprezá-lo. Ademais, tem permitido trocas significativas para o desenvolvimento de atividades integradas de ensino, pesquisa, extensão e cultura, contribuindo para a busca compartilhada de alternativas didáticas orientadas para práticas educativas que possibilitem articulação e dinamização do processo de ensino e aprendizagem. Outro aspecto inerente ao PIBID Geografia é a contribuição para a valorização do trabalho docente e estabelecimento de relações colaborativas entre a escola de Educação Básica e a Universidade.

Palavras-chave: Política educacional; Iniciação à docência; Ensino e aprendizagem em Geografia; Alfabetização geográfica e Linguagens.

\section{ABSTRACT}

The aim of this paper is to analyse the formative process of Geography teachers, considering new policies that have been created recently in Brazil. These policies aim to improve the teachers practical scope, which means an improvement in their formation and also in the formation of the student at the Elementary School years. In that way, we observe the results that were accomplished by the Institutional Program of Scholarship for Teaching Process Introduction (PIBID in Portuguese), program which was created as a Brazilian political action for the improvement of teachers' formation from the Elementary School. This program grants scholarships for undergraduated students at university, who are going to be supervised by professors who are managing these projects. Moreover, this program awards scholarships for other supervisors (teachers) from the Elementary Schools in order to encourage the link between the schools and these projects. These academics from the university experience the schools' issues and challenges, the student formation reality outside school, as well as the school schedule planning process. Through the PIBID/Geography/UFGD, the profits of the future teachers' formation are highlighted by the experience of the activities. These activities show the understanding of new knowledges, languages and practices which aims the overcome of the didactic book. Nevertheless, we are not pointing that the didactic book is a worthless tool. Moreover, these activities are allowing real gain to the development of learning processes (which are linked to the teaching area, the research scope, the social actions scope and the cultural area). Besides, these activities are really helping to find and share didactic 
alternatives for educational practices which could enable a better organization and evalution of the teaching and learning process. Another main aspect about PIBID/Geography/UFGD is its contribution for the teacher's work valorization and for a consolidate partnership between the Elementary School and the University.

Keywords: Educational policies; teaching introduction; teaching and learning Geography; geographical literacy and languages.

\section{INTRODUÇÃO}

É objetivo deste trabalho, analisar o processo formativo dos professores de Geografia, considerando políticas de governo instaladas recentemente no Brasil, cujas proposições se apresentam para melhorar a prática docente, a formação do professor e a formação do estudante, na educação básica. Referimonos ao Programa Institucional de Bolsa de Iniciação à Docência (PIBID), que tem sido implementado por meio da Coordenação de Aperfeiçoamento de Pessoal de Nível Superior (CAPES) ${ }^{1}$ e contado com adesão das Instituições de Ensino Superior (IES) ${ }^{2}$.

Segundo o Presidente da CAPES, Jorge Almeida Guimarães, em Apresentação do documento avaliativo da Fundação Carlos Chagas:

\footnotetext{
Com seu desenho, o PIBID é formação inicial para os alunos das licenciaturas; é, também, formação continuada para os professores das escolas públicas e para os professores das instituições de ensino superior participantes, abrindo-lhes amplas oportunidades de estudos, pesquisa e extensão. A ação dos Licenciandos e de seus orientadores tem o potencial de elevar a qualidade do trabalho nas escolas públicas e nas instituições formadoras.

De fato, nesse período ainda curto de sua existência, o PIBID já vem sendo reconhecido como uma política pública de alto impacto na qualidade da formação de professores. (FUNDAÇÃO CARLOS CHAGAS, 2014, p.5)
}

A proposta de atuação do Programa possibilita expressar a magnitude de ideias e teorias que devemos nos apropriar para avaliar tal política educacional, que é de fato, governamental, mas que se pretende pública, como aponta o então presidente da CAPES, e cujo recorte é a proposta PIBID que vem sendo

1 http://www.capes.gov.br/educacao-basica/capespibid Acesso em 22/09/2016

${ }^{2}$ Ver GATTI, B.A.; BARRETO, E.S.S. e ANDRÉ, M.E.A. (2011). 
desenvolvida no Curso de Geografia (2009-2015), na Universidade Federal da Grande Dourados (UFGD), que está entre os cursos de Graduação que iniciaram no Programa, desde o primeiro edital, lançado em dezembro de 2007, mas que efetivamente teve atividades iniciadas em $2008 .^{3}$

Tem sido produzido vários trabalhos que permitem a reflexão sobre o PIBID. Carvalho e Carvalho Filho (2010, p.1), que analisam experiência vivida em Viçosa (ES) afirmam: "A aproximação da universidade ao ensino básico proporciona aos estudantes universitários a oportunidade de colocar em prática o aprendizado teórico, acrescentando muito para a formação profissional.”

Comungamos da mesma opinião dos autores e, nesse sentido, entendemos ser significativo avaliarmos o Programa, tomando como referencial a experiência do PIBID/Geografia, executada no Curso de Geografia da Universidade Federal da Grande Dourados, reconhecendo que a integração da escola e da universidade é uma demanda importante, mas que os contatos, historicamente, têm sido quase sempre conflituosos e permeados por dúvidas sobre sua capacidade de plena realização. (ABREU, 2013).

\section{Para começar vamos pensar a formação de professores ... algumas reflexões!}

O debate acerca da Formação de Professores está permeado, essencialmente, pela relação ensinoaprendizagem enquanto processo inerente à formação dos sujeitos e suas práticas na sociedade contemporânea. Trata-se da necessidade de compreender a importância da formação do professor, da teoria e prática docente, bem como do modo como tal condição pode contribuir (ou não) para a definição de conteúdos e procedimentos de ensino e incorporar o método, que expressa o saber e o fazer dos professores. (ABREU, 2012).

De acordo com Gramsci (1978), a escola é um aparelho privado da sociedade civil e dos interesses das frações dominantes da sociedade, todavia é também, contraditoriamente e simultaneamente, porta de

\footnotetext{
${ }^{3}$ Projeto de Pesquisa "Ensino de Geografia na Educação Básica: uma avaliação do Programa Institucional de Bolsa de Iniciação à Docência (PIBID). Resultados e Proposições”. Aprovado pela UFGD e financiado pela Fundect/MS, em 2015, sob a coordenação da Prof $^{\text {a }}$ Dr $^{\text {a }}$ Silvana de Abreu.
} 
entrada para outras concepções de mundo e influências, podendo conduzir à superação dos valores vigentes pela expressão de seu contrário. Entendemos como o autor, essa é uma das razões pelo qual a educação escolar é importante, sob qualquer base teórica e epistemológica.

Nesse contexto, professores se constituem, em tese, em "peças" essenciais, mas que se contribuem ou não para o status quo, são idealizados como reprodutor de conhecimentos que são produzidos por outros e em outros lugares, que não a escola. Essa concepção é tão expressiva que professores a incorporam e reproduzem a ideia de que seu trabalho seria dar aulas. De outra parte, a administração da escola, bem como os governos, afirmam e reconhecem essa mesma concepção sobre o fazer do professor e para isso, por 20 ou 40 horas semanais, em horários estabelecidos, os professores estão na escola e nas salas de aula para "darem aulas". Assim, os professores são pagos pelas aulas que “entregam" e no contexto das relações de trabalho mercantis, como não têm tempo de produzir, se transformaram em "repassadores" ou "atravessadores" de conhecimentos, condição que desqualifica o seu papel e isso se reflete na sua remuneração e na desvalorização da profissão.

No dizer de Giroux (1988) o professor tem sido visto como um prestador de serviço; um mediador entre um saber científico produzido em outra esfera e de dimensão padronizada e a disciplina escolar para o qual está, em tese, apto a ensinar. Essa é uma condição, que na segunda metade do século XX alimentará a indústria do livro didático, a ampliação do número de vagas no ensino superior e verdadeiras fábricas de diplomas (licenciaturas curta ou plena), favorecidas pela proliferação das faculdades privadas, em detrimento de investimentos na formação dos professores em Universidades Públicas. Estas, as Públicas, seriam lócus principalmente de cursos de "excelência” para o "Brasil moderno e industrial do milagre brasileiro". Referimo-nos aos cursos de graduação em medicina, engenharias, odontologia, contraditoriamente abertos a quem poderia pagar por cursinhos específicos para terem acesso às vagas, uma vez que apenas com o ensino "disponível" como saber escolar, não era possível adentrar nas universidades públicas, sobretudo nos cursos "mais concorridos". Estabeleceu-se, portanto, uma discriminação velada, pois o caminho para esses cursos só poderia ser percorrido pelas classes sociais mais abastadas. (ABREU, 2012) 
Curiosamente, dentro do mesmo processo de modernização do País, os cursos de formação de professores criados no interior desse mercado (faculdades privadas) responderiam de modo mais eficiente que a Universidade Pública à política de universalização e expansão da rede escolar no Brasil, que começou nos anos de 1950 e se intensificaria nos anos 60 e 70, no contexto dos Governos Militares, do Programa de Integração Nacional (PIN), do Programa MEC-USAID e das Leis 4.024/1961 (Lei de Diretrizes e Bases da Educação); 5.540/1968 (sobre o ensino superior) e a Lei 5.692/1971(que trata do ensino médio), que embalariam a universalização da escola de nível "primário"; tornaria obrigatório o ensino técnico em nível secundário, visando formação de mão de obra, e limitaria o acesso ao ensino superior, que se dedicaria a formar profissionais para atender o projeto de crescimento econômico que integraria o território nacional ao capitalismo mundial, gestado para dar condições ao cumprimento de seu "novo/velho" papel na divisão internacional do trabalho e que se realizaria pela industrialização e crescimento do mercado interno e, ao mesmo tempo, a produção de matérias-primas para exportação, para atender ao mercado externo.

A base da formação escolar, em todos os níveis, estaria voltada para o trabalho e isso estava relacionado com os objetivos e prioridades do chamado "Brasil Potência"4

Os professores formados nesses cursos, chamados "particulares", de qualidade questionável, serão em grande parte aqueles que assumirão as “matérias" de matemática, estudos sociais, comunicação e expressão, ciências, educação moral e cívica, nas escolas públicas, primárias e secundárias, por todo o País, apoiados pela indústria de livros didáticos, inclusive porque, para compor carga horária, os professores assumiam diferentes matérias, para as quais nem tinham formação/habilitação e os livros didáticos podiam contribuir sobremaneira na solução da condição imposta. Algumas dessas matérias estavam em consonância com a formação para o trabalho ("Práticas comerciais"; "Práticas do lar"; "Desenho técnico"; "Análise de solo"; "Desenho Industrial” etc) e eram assumidas por profissionais de todas (e quaisquer) áreas de conhecimentos, numa evidente precarização da relação

\footnotetext{
${ }^{4}$ Sobre "Projeto Brasil Potência" e suas implicações para a educação, ver: COVRE (1983).
} 
ensino/aprendizagem. De fato, o processo de universalização da formação profissional (técnica) em nível médio foi um grande fiasco do "Brasil Potência".

Nessa perspectiva, é preciso reconhecer que a pouca (ou nenhuma) importância dada ao profissional "professor" tem muitos lastros, sendo um deles, inclusive, a divisão de trabalho entre as diferentes classes sociais, já que lecionar, historicamente, é "tarefa" ou "oportunidade" dos menos abastados, ou ainda, na pior concepção, dos menos capacitados, já que os "melhores" passavam nos vestibulares para os cursos de excelência.

A redemocratização política no País e a recomposição dos movimentos sociais, nos últimos trinta anos (1985-2015), a nova LDB, de $1996^{5}$, a expansão do número de vagas nas Instituições de Ensino Superior Públicas, sobretudo Federal ${ }^{6}$, tem contribuído para a consolidação de outros olhares sobre a formação do professor. Além disso, é preciso considerar também as condições que envolvem mudanças proporcionadas pela indústria da informação e informatização, com acesso facilitado à tecnologia e a rede de internet, seja pelos estudantes, seja pelos professores, ainda que de modo não muito sistematizado.

Segundo Azevedo (2009), as Salas de Tecnologia Educacional (STE) nas escolas datam do final do século passado, 1997. Elas foram criadas pelo Governo Federal por meio do PROINFO - Programa de Informática na Educação - e são laboratórios de informática instalados nas escolas públicas, com a justificativa de melhoria na qualidade do ensino.

${ }^{5}$ Lei de Diretrizes e Bases da Educação Nacional. Lei nº 9.394, de 20 de dezembro de 1996. Estabelece as diretrizes e bases da educação nacional.

6 Destacam-se as leis de expansão da Rede Federal (IFES) e de criação dos Institutos Federais (Lei 11.892/2008 - Institui a Rede Federal de Educação Profissional, Científica e Tecnológica, cria os Institutos Federais de Educação, Ciência e Tecnologia, e dá outras providências.), mas também as Leis que criaram Universidades Federais a partir de 2005 como: Lei 11.145, de 26/07/2005 que cria a Universidade Federal do ABC Paulista; a Lei 11.153, de 29/07/2005, que cria a Universidade Federal da Grande Dourados; a 11.151, de 29/07/2005, que cria a Universidade Federal do Recôncavo da Bahia, entre outras que foram criadas em 2005 e a partir daí. A rede federal de Universidades Federais de Ensino saiu de 45, em 2002, para 63, em 2014. 
Nos governos do Presidente Luiz Inácio Lula da Silva (2003/2006 e 2007/2010), além das STE, foram criadas políticas de inclusão digital, com a liberação de computadores pessoais para alunos e professores. É o caso do Projeto Computador Portátil para Professores, por exemplo. A diferença fundamental é conceitual (inclusão digital) e prática pelo acesso individual. Diversas STE têm restrição para uso, seja porque não contam com servidor técnico disponível e é difícil para os professores o seu uso, seja porque a obsolescência dos equipamentos é muito rápida (em verdade, imediata), ou ainda, porque na prática tem sido a definição de tarefas a serem realizadas, pelos alunos, em computadores, na internet, o que transforma a STE, muitas vezes em lan house pública para acesso dos estudantes.

É evidente que os professores necessitam acompanhar as mudanças tecnológicas a fim de adaptar-se e incorporá-las ao seu fazer pedagógico. Porém, tendo em vista que parte significativa dos professores está acostumada com o ensino tradicional, linear, baseado em textos e retórica, a necessidade de letramento digital, o uso de novas tecnologias e mídias tem sido uma demanda obrigatória e desafiadora.

Consideramos que o investimento na formação de professores é investimento acertado para melhorar a escola, na medida em que aprender e ensinar não se constitui em condições opostas, antes pelo contrário. Moran (1999), em palestra proferida no evento "Programa TV Escola" fala do inesperado existente na relação ensino/aprendizagem, sobretudo nos tempos de informação rápida e massificada:

Avançaremos mais se soubermos adaptar os programas previstos às necessidades dos alunos, criando conexões com o cotidiano, com o inesperado, se transformarmos a sala de aula em uma comunidade de investigação. Ensinar e aprender exige hoje muito mais flexibilidade espaçotemporal, pessoal e de grupo, menos conteúdos fixos e processos mais abertos de pesquisa e de comunicação. Uma das dificuldades atuais é conciliar a extensão da informação, a variedade das fontes de acesso, com o aprofundamento da sua compreensão, em espaços menos rígidos, menos engessados. Temos informações demais e dificuldade em escolher quais são significativas para nós e conseguir integrá-las dentro da nossa mente e da nossa vida. 
Para além da informação e informatização, no âmbito da escola e do cotidiano de alunos e professores, a sociedade moderna vem impondo à escola e ao professor temáticas desafiadoras que estão respaldadas nos avanços dos direitos humanos e de cidadania, quais sejam: igualdade e respeito à diversidade étnica, racial, de deficientes físicos, homossexuais, de gênero e cuidado com meio ambiente. Tudo isso implica em novos conceitos culturais e práticas no interior da escola e também no interior dos cursos de formação docente.

É fato, portanto, que a questão da formação do professor, em tempos recentes, esta permeada pela ideia de inacabável, inesperado e incorporação de novos referenciais (e leis) e práticas que colocam (pré)conceitos a serem superados. Essa condição contribui para que a distância entre a escola pública e a academia se amplie significativamente, fomentando resistências a leituras e reflexões sobre a práxis pedagógica. Cotidianamente, essa relação desgastada se expressa em argumentos: "eles não estão em sala de aula, não sabem o que é ter "esses alunos"” ou, ainda, "o que se aprende na graduação não serve na prática”. (OLIVEIRA e PAZ LIMA, 2007).

Na mesma proporção o discurso da academia tende a ser propositivo, indicando experiências que deram certo e possibilidades de trabalho numa perspectiva crítica e/ou criativa, mas que muitas vezes dialoga pouco com o professor do ensino básico, que pela prática vivida, desconfia que este mundo de possibilidades simplesmente "não existe" porque a realidade é "outra"!

De fato, é preciso reconhecer e concordar que a realidade é mesmo outra. Além disso, é preciso também pensar sobre o fato de que os professores que estão na escola e estão submetidos aos limites do ensino básico, sairam da universidade, então a crítica ao professor precisa ser também uma avaliação crítica ao processo formador, inclusive. 
Uma condição que está posta, desde a formação, é a necessidade de incentivar o professor (e também o futuro professor) a pesquisar, dando-lhe condições efetivas para tal empreendimento, de modo que suas práticas possam ser revertidas em objetos significativos de aprendizagem e produção de conhecimento (SOCZEK, 2011). Outra possibilidade, e o PIBID se coloca nessa perspectiva, é avançarmos para construção de cumplicidade na formação de sujeitos para a sociedade e para a vida (inclusive, o trabalho): escola e universidade.

Concordamos com o autor. Sem produção de conhecimento o que sobra é a reprodução. Para romper com a lógica em pauta é preciso romper com o modelo que pensa o processo ensino-aprendizagem e a formação de crianças, jovens (e, inclusive dos próprios professores), sob a lógica temporal estática, medida em "hora-aula".

Como superar o aulismo se ele está impregnado na própria ideia construída sobre o professor? No caso do professor de Geografia, inclusive, essa condição se agrava na prática que se consolidou de construção do conhecimento geográfico, no interior das escolas, que foi historicamente baseada na memorização, na descrição, associadas a saberes superficiais e de cunho enciclopédico, com pouca capacidade de agregação de crítica e de autonomia.

No dizer de Rua (1993, p.3) a Geografia deve favorecer “(...) capacidade de refletir criticamente sobre a sociedade em que vive e sobre o espaço que ocupa e, muitas vezes ajuda a construir." O limitado contato com o texto do livro didático e sua reprodução não dão conta da condição formativa expressa pelo autor, sobretudo porque, para serem vendidos por todo o país, os livros "apresentam uma visão metropolitana e branco-ocidental da realidade, que singulariza valores e padroniza o que é eminentemente diverso/contraditório.” (ABREU, 2012, p.39).

O resultado desse processo, as avaliações elaboradas a partir do Conselho Nacional de Educação e Ministério da Educação já confirmam: a escola e a educação básica estão em profunda crise de significado e a Universidade, fundamentalmente a pública, vem sendo chamada a contribuir. A escola 
do conteúdo tem se revelado incapaz de garantir o aprendizado do conhecimento científico a que se propõe, mas fundamentalmente, por ter se mostrado incapaz de formar seres humanos na sua essência, qual seja: criativos, observadores e críticos.

Vimos afirmando sobre a necessidade de mudar os cursos de formação e a relação com a escola, que não deve ser apenas lócus de estágio curricular obrigatório. É preciso superar dicotomias arraigadas. É preciso romper com a formalização lógica do pensamento para a qual temos muitas críticas, mas não avançamos. É preciso outras formas de ensino/aprendizagem; não apenas formular a crítica à escola e à universidade. É preciso a negação para a afirmação de novas bases. (ABREU, 2012).

Daí, entendermos que algumas possibilidades têm sido colocadas como políticas governamentais e que precisamos nos apropriar e incorporar como políticas públicas, de Estado, para além de governos. Fazemos menção especificamente ao Programa Institucional de Bolsa de Iniciação à Docência (PIBID), criado como política de governo para promover a qualidade no ensino na escola básica. ${ }^{7}$

As Instituições de Ensino Superior públicas, comunitárias, confessionais e filantrópicas, sem fins lucrativos, que oferecem cursos de licenciatura, vem implantando projetos (evidentemente com condições e avaliações diferenciadas), que envolvem licenciandos-bolsistas, professores-supervisores, das escolas, e coordenadores de área, da universidade participante.

Todos os sujeitos envolvidos têm bolsas para incentivar o desenvolvimento dos projetos e, sobretudo, para incentivar os acadêmicos, que passam a ter a vivência do debate das questões que envolvem a escola, a formação (fora da sala de aula), inclusive participando de situações de planejamento e/ou das atividades desenvolvidas na escola parceira, da qual passam a fazer "parte".

\footnotetext{
${ }^{7}$ Ver: http://portal.mec.gov.br/index.php?option=com_docman\&view=download\&alias=16762-balancosocial-sesu-2003-2014\&category_slug=dezembro-2014-pdf\&Itemid=30192 Acesso em 19/09/2016. Trata-se da sistematização de todos os programas e projetos que envolve a Secretaria de Ensino Superior, inclusive as políticas de formação de professores impressas a partir de 2003 no Brasil.
} 
O PIBID é uma iniciativa para o aperfeiçoamento e a valorização da formação de professores para a educação básica. O programa concede bolsas a alunos de licenciatura, a participantes de projetos de iniciação à docência desenvolvidos por Instituições de Educação Superior (IES) em parceria com escolas de educação básica da rede pública de ensino. Os projetos devem promover a inserção dos estudantes no contexto das escolas públicas desde o início da sua formação acadêmica para que desenvolvam atividades didático-pedagógicas sob orientação de um docente da licenciatura e de um professor da escola. http://www.capes.gov.br/educacaobasica/capespibid

Acesso em 06/08/2015. (grifo nosso)

A bolsa de Iniciação à Docência (ID), assim como a de iniciação científica (IC), contribui para o processo formativo do acadêmico, futuro professor, com possibilidade de desenvolvimento de pesquisas no campo do ensino de Geografia, inclusive. Mas, o incentivo da bolsa é ponto reconhecido pelos acadêmicos bolsistas (42\%) como fundamental para entrada e permanência no curso e no Programa. Referimo-nos a condição de existência desses estudantes, que são alunos de um curso noturno, que, em maioria, viajam diariamente de seus municípios para estudar e participar das atividades do programa e são, em boa parte, trabalhadores (50\%). Esse quadro reflete como é a realidade do estudante do curso de licenciatura em Geografia, em que as atividades necessitam considerar a condição de trabalhadores dos seus acadêmicos. Destaca-se que é ponto positivo do Programa a possibilidade dos acadêmicos serem bolsistas e poderem trabalhar. No modelo idêntico do Programa de Iniciação Científica (CNPq), por exemplo, metade dos alunos em processo de formação no PIBID seriam impossibilitados de participar.

Ademais, o PIBID trás para dentro da relação ensino-aprendizagem o professor da escola, também bonificado (bolsa de supervisor) para dedicar-se aos projetos aprovados e dos quais também é sujeito. A nossa pesquisa constatou que as professoras que participaram e participam do PIBID de Geografia/UFGD (2009-2015) valorizam-no como um processo de formação continuada, na medida em que ressaltam que prevalece a ideia do "novo" e a preocupação com a formação, para si e para o outro. Essa é sem dúvida uma compreensão relevante para o processo de avaliação do Programa. 
Como destacado por Gatti, André e Ferragutti (2014, p.10) :"O objetivo desse programa está associado à importância crescente de políticas de indução de valor e mudanças em posturas formativas de docentes para a educação básica no âmbito das Instituições de Ensino Superior (IES).” Sem dúvida, o Programa põe em movimento todos os segmentos do processo formador.

Segundo Soczek (2011), o debate sobre a formação de professores tem se tornado políticas e tem sido cada vez mais estimuladas, considerando as demandas sociais e o aporte jurídico da LDB - Lei de Diretrizes e Bases da Educação (Lei N. 9394/1996). O fato é que as condições que a legislação aponta como válidas para o desenvolvimento da educação nacional, associadas com a avaliação realizada pelo Ministério da Educação, em todos os níveis, colocam demandas a serem absorvidas pela Rede Pública Escolar, fundamentalmente, por gestores e professores.

É nesse contexto que o PIBID foi lançado pelo Governo Federal, em dezembro de 2007, com o discurso de atuar na formação do professor e na qualidade da educação básica e se constitui em desafio de realização, consolidado como "Meta 15", que trata da formação do professor ${ }^{8}$, no Plano Nacional de Educação (LEI 13.005/2014).

De acordo com o Ministério da Educação:

O Programa oferece bolsas de iniciação à docência aos alunos de cursos presenciais (...). O objetivo é antecipar o vínculo entre os futuros mestres e as salas de aula da rede pública. Com essa iniciativa, o PIBID faz uma articulação entre a educação superior (por meio das licenciaturas), a escola e os sistemas estaduais e municipais. A intenção do Programa é unir as secretarias estaduais e municipais de educação e as universidades públicas, a favor da melhoria do ensino nas escolas públicas em que o Índice de Desenvolvimento da Educação Básica (Ideb) esteja abaixo da média nacional, de 4,4. (grifo nosso) http://portal.mec.gov.br/ .Acesso em $06 / 08 / 2015$.

\footnotetext{
${ }^{8}$ Sobre políticas públicas para formação do professor no âmbito do PNE e META 15 ver http://www.observatoriodopne.org.br/metas-pne/15-formacao-professores Acesso 06/08/2015
} 
A Rede Escolar (pública) de Mato Grosso do Sul está vinculada ao Sistema Estadual de Ensino e de acordo com o último censo INEP/IDEB para a Região Centro-Oeste ficou na média nacional. Não há o que comemorar. Há grande distância entre a realidade, os índices e o que se espera do processo formativo nas escolas de ensino fundamental e médio. As metas são numerais e são médias, mas os resultados buscados precisam ser também reais, coletivos e é esse o desafio. Pela natureza do Programa, o MEC viu na Coordenação de Aperfeiçoamento de Pessoal de Nível Superior (CAPES) a possibilidade de implementação da proposta, em parceria com as Instituições de Ensino Superior. Assim, o PIBID foi criado e pensado para atuar como uma política educacional para a escola básica, mas cujas ações são integradas e voltadas fundamentalmente para a intervenção no/do Ensino Superior.

É um desafio que precisamos encarar como estratégia para darmos vazão a compreensão de que os processos formalizados precisam superar o limite da sala de aula, incorporar a produção do conhecimento (pesquisa) como guia/referencial de formação e os eixos de conhecimento como possibilidades de processos formativos autônomos, em que o aluno é sujeito em sua formação e os saberes não-científicos, como refere-se Nunes (2011), inerentes a sua vivência, possam ser incorporados não apenas como uma técnica para o estagiário ser "mais crítico", mas como uma ferramenta de formação dentro da própria universidade.

Reitera-se que a estrutura advinda do Programa PIBID tem proporcionado, no caso do Projeto de Geografia/UFGD, o que nem mesmo a ampliação da carga horária de Prática de Ensino e Estágio Supervisionado (400hs $+400 \mathrm{hs})$ foi capaz de superar: a dicotomia conteúdo/método, mostrando-se como instrumento revelador de avanços.

\section{O PIBID de Geografia/UFGD: incorporando diferentes linguagens, construindo caminhos, formando sujeitos}


A análise está motivada por processos que envolvem a trajetória profissional (de ensino, pesquisa e extensão) dos pesquisadores envolvidos. Um aspecto importante é a experiência com a formação de professores de Geografia, trabalhando inclusive com as disciplinas de Prática de Ensino e Estágio Supervisionado, em Instituições de Ensino Superior (UFGD e UFMS) e que em seus diferentes tempos somam mais de duas décadas de atuação e dedicação a reflexão do ensino de Geografia, formação e relação teoria/prática. Há, ainda, vinculação com a formação em pós-graduação, com envolvimento dos docentes com o Programa de Pós-graduação em Geografia da Universidade Federal da Grande Dourados, desde sua criação, em 2006. Finalmente, é mister reforçar o envolvimento e participação com/no Programa PIBID/UFGD. ${ }^{9}$

O contato com a realidade das escolas, seja por meio da disciplina Estágio Supervisionado, acompanhando estagiários, seja especialmente pela experiência no PIBID, tem indicado a necessidade de reflexão sobre elementos específicos dessas realidades, no que diz respeito ao tratamento de determinados temas nas aulas de Geografia, mas fundamentalmente, no campo da relação ensino/aprendizagem - teoria/prática.

Destaca-se, principalmente, a própria construção de conceitos, valores e conhecimentos em extensão, por meio de outras linguagens e práticas que ocorrem nos turnos, mas também nos chamados contraturnos escolares. Em trabalho que analisa o PIBID Geografia/UFGD, em seu primeiro ano de atividades em escolas (2009), ficou referenciado o papel do Programa como apoio pedagógico aos estudantes. O Programa atuou no reforço (fora da aula) a aprendizagem dos conteúdos em extensão tratados nos horários de aula. (MUNIN, PIRES \& BENITES, 2010)

A análise discursiva de documentos, publicações em eventos, dizeres de professores e ID, em diferentes situações que expressam a participação no/do Programa, nos remete a reconhecer avanços que tem relação com a aproximação dos licenciandos à realidade do ensino, com uma inserção assistida por

\footnotetext{
${ }^{9}$ O PIBID de Geografia/UFGD tem duas coordenações de área, organizadas em dois grupos de 12 ID, totalizando 24 bolsistas (ID).
} 
professores mais experientes, com oportunidade de investigação dos problemas que interferem no ensino, assim como de experimentação e inovação pedagógica.

Essa condição não tem sido plenamente realizada com os estágios supervisionados, que tem 400 horas. Posto isso, o campo de nossa análise é tanto o debate da formação inicial e continuada do professor, como a análise de uma política que entrou na pauta do Plano Nacional de Educação (2014) e, contraditoriamente, como Política a sofrer cortes de recursos, no contexto do ajuste fiscal, desde meados de 2015. Sem dúvida essa condição também é elemento de justificativa para nos dedicarmos a reflexão, ainda que tais inquietações já sejam reticentes e comparecem em trabalhos anteriores (ABREU, 2012 e ABREU e SOUZA, 2014).

Em "Carta Aberta", no dia 22/06/2015, o FORPIBID - Fórum Nacional dos Coordenadores Institucionais do PIBID - chama a atenção da sociedade e do Governo para o Programa e suas realizações. Alguns números nacionais se fizeram presentes no documento que aqui transcrevemos:

Com investimentos do Ministério da Educação e da CAPES, em 2009, o PIBID foi implantado em 43 Instituições de Nível Superior (IES), 266 escolas, concedendo 3.088 bolsas. O sucesso do Programa vem justificando a sua ampliação, chegando a 2015 com 284 Instituições de Nível Superior (IES), 5.898 escolas e 90.254 bolsas concedidas ${ }^{10}$

O movimento que ocuparia as redes sociais, como \#ficapibid, para além da manutenção das bolsas e do Programa, expressou o crescimento e a grandiosidade dessa política em termos de abrangência nacional ${ }^{11}$. Ainda, a mesma "Carta Aberta" expressa: "O Pibid foi o primeiro e é único no enfretamento do desafio de formar mais e melhores professores para a educação básica". Sem dúvida esse é um sentimento massificado e envolve todos os sujeitos desse processo e justifica a investigação que vimos realizando.

\footnotetext{
${ }^{10}$ www.pibid.ufv.br/wp-content/uploads/CARTA-FORPIBID.pdf Acesso em 10/07/2016.

${ }^{11}$ https://www.facebook.com/groups/1600686786872263 . Acesso em 10/07/2016
} 
No campo da formação de professores, a UFGD implantou o Programa Institucional de Bolsas de Iniciação à Docência (PIBID), em 2008, e já na sua primeira proposta o curso de Geografia foi inserido ${ }^{12}$.

O envolvimento do curso de Licenciatura Plena em Geografia no Programa Institucional de Bolsa de Iniciação à Docência (PIBID/UFGD), desde o início, se justificou na necessidade de criação de condições materiais e pedagógicas que integrassem os diferentes sujeitos responsáveis pela educação, quer sejam os futuros profissionais ou os professores que já fazem parte do processo de ensino/aprendizagem e necessitavam de novos investimentos, que ampliassem os conhecimentos adquiridos na formação inicial.

As propostas apresentadas no "Projeto Geografia" estão em consonância com as atuais orientações curriculares para a Educação Básica, o que exige, metodologicamente, que essas atividades integrem também os conhecimentos que os professores devem desenvolver durante o curso de licenciatura. As ações propostas em Geografia visam, primordialmente, que sejam pensadas alternativas para o ensino desse campo de conhecimento, na Educação Básica, sem romper com a autonomia do professor que nela atua, nem tampouco impondo condições, mas que desempenham a função de facilitar o aprendizado.

Assim, as diferentes linguagens constituem o núcleo de atuação e de formação dos acadêmicos deste curso de graduação e que está baseado em vários autores entre os quais citamos Pereira e Seemann (2013) e Oliveira Jr. e Girardi (2011).

Com a execução das ações propostas, procurou-se proporcionar aos sujeitos envolvidos com a licenciatura em Geografia e com o exercício da docência na educação básica, conhecimento sobre a área de atuação, sobre o curso e as possibilidades de abordagens, as novas tecnologias e linguagens

\footnotetext{
${ }^{12}$ Disponível em: http://www.capes.gov.br/educacao-basica/capespibid/editais-e-selecoes e http://www.capes.gov.br/images/stories/download/bolsas/Projetos_Aprovados-PIBID_1Publicacao.pdf Acessos em:21/09/2016.
} 
disponíveis. Pretendeu-se ainda, com a implementação concomitante das ações propostas, que ocorressem trocas mais significativas para o desenvolvimento de atividades integradas de ensino, pesquisa, extensão e cultura, contribuindo, nesse sentido, para a busca compartilhada de alternativas didáticas, orientadas para práticas educativas que possibilitem mais articulação, dinamização e flexibilização do processo de ensino e de aprendizagem. Trata-se, sobretudo, de capacitar os acadêmicos bolsistas (ID), futuros professores, para o domínio teórico-prático das linguagens artísticas no processo de alfabetização geográfica. Em pesquisa realizada com os acadêmicos que foram ou são bolsistas no PIBID Geografia, observou-se que prevaleceu a preocupação com a prática docente e com a possibilidade de formação mais diferenciada como elemento fundamental para terem procurado o Programa, revelando que as leituras, discussões e estudos realizados no interior do Projeto são motivadores e comungam com os objetivos apresentados na Proposta institucional, qual seja, a diferenciação da relação teoria-prática àqueles que são contemplados e participantes.

Outro aspecto importante inerente ao PIBID de Geografia (UFGD) é a possibilidade de apoiar a pesquisa didática e o ensino por meio de experiências vividas por acadêmicos e professores na participação em eventos, produção de textos e sistematização de experiências desenvolvidas. Essas condições normalmente não são estimuladas no cotidiano escolar, tampouco no estágio supervisionado. Indubitavelmente, a existência do Programa, os objetivos de sistematização e produção, que o próprio projeto indica, contribuem para tais realizações. Entendemos que a participação das professorassupervisoras produzindo textos, apresentando trabalhos, participando de projetos de pesquisa, são diferenciais que corroboram para mudanças na prática. Quando chamadas a refletir sobre o Programa, foi recorrente a possibilidade de estudar como condição relevante. Mas, também, verificamos a preocupação com a teoria e a prática e também com a melhoria da escola.

O conjunto de condições que o Programa proporciona, observa-se, tem contribuído para a valorização do trabalho docente e para o estabelecimento de relações colaborativas mais estreitas entre a escola de Educação Básica e a Universidade, com atividades de ensino, pesquisa e extensão ligadas ao curso de licenciatura. São trabalhos monográficos de conclusão de curso, envolvimento dos acadêmicos nas 
"feiras científico-culturais escolares", trazendo temas transversais (ou curriculares) e sempre pautados em questões atuais, para fomentar o debate acerca da realidade vivida. Em 2014, dois temas embalaram os trabalhos: copa do mundo de futebol e eleições presidenciais no país.

Como resultado desse trabalho, os estudantes do ensino médio produziram imagens que foram reproduzidos no muro de uma das escolas e criaram o "circuito cidadão", com as imagens produzidas pelos alunos durante as intervenções dos acadêmicos, e que era uma base de diálogo com quem visitava o "circuito". Essa experiência que carrega o inesperado foi rica de significado na sua realização, mas sem dúvida é a expressão de experiências não convencionais no âmbito dos processos formalizados nas escolas, sobretudo nas públicas.

Ainda em 2014, dentro do projeto de Geografia, foi possível realizar expedições geográficas. Uma foi realizada no Museu de Arte Contemporânea de Mato Grosso do Sul (MARCO), em Campo Grande MS, e permitiu que os futuros professores exercitassem a análise de obras de arte, identificando elementos estéticos, contextos de elaboração, técnicas, entre outros, compreendendo as especificidades dessas linguagens. Outra expedição, foi a visita a duas escolas do campo, sendo uma municipal, em assentamento de trabalhadores rurais, e a outra em um acampamento de sem-terra, às margens de uma rodovia estadual, ambas no município de Itaquiraí (MS).

O objetivo foi propiciar aos acadêmicos-bolsistas contato com experiências de ensino em escolas inseridas em contextos diferentes daqueles que fazem parte do seu cotidiano. O resultado foi a organização de uma mostra fotográfica que teve como tema "Escola no campo, escola do campo!", nascido dos debates realizados com os diferentes sujeitos e ofertado como conhecimento sistematizado aos acadêmicos da UFGD que circularam pelo saguão da Faculdade de Ciências Humanas e se dedicaram a conhecer e discutir.

Nesse sentido, parece-nos correta a assertiva de Gatti, André e Ferrogutti (2014, p.107/8), os quais argumentam categoricamente que o PIBID: 
(...) vem criando condições para um processo de formação consequente para o desenvolvimento profissional dos docentes de modo que possam participar do processo de emancipação das pessoas, o qual não pode ocorrer sem a apropriação dos conhecimentos. O papel da docência na educação básica é vital na preservação de nossa civilização e no desenvolvimento das pessoas como cidadãos que possam ter participação efetiva para a melhoria das condições de vida em suas comunidades.

Evidencia-se, deste modo, a significativa efetividade do PIBID no que se refere a formação inicial e continuada dos professores, assim como o papel da docência na educação básica para a formação de sujeitos. A experiência vivida no MARCO foi retratada como a primeira experiência em um museu, pela maioria absoluta de ID que dela participaram. Isso é significativo e formador!

\section{Para finalizar e resistir ...}

São muitas as experiências que vêm sendo realizadas desde a implantação do PIBID na Universidade e na Geografia, de modo que se faz necessário aprofundar os instrumentos de avaliação, com vistas a contribuir com a política governamental, mas, sobretudo, com a política educacional que prima pela qualificação da formação inicial e continuada do professor.

O curso de Geografia da UFGD tem alcançado boas notas nas suas avaliações. Isso reforça o compromisso de investir sempre mais em possibilidades que garantam aos estudantes melhor formação para a docência. Por outro lado, na Educação Básica, ainda se percebe lacunas cuja manutenção da parceria UFGD/CAPES/Escolas públicas pode ser fundamental para o processo de superação.

Essa integração parece contribuir, sobremaneira, na definição de ações estratégicas para a melhoria da qualidade do ensino, como a necessidade de diálogo entre a escola e a academia, busca de novos espaços de inserção, de trocas, de descobertas, de experimentação de novas metodologias, diálogos e linguagens. (NUNES, 2011) 
Ademais, partilharmos da concepção de que o PIBID/Geografia/UFGD tem possibilitado a vivência da inicia ᄀção à docência, em diálogo com a formação teórica ofertada pela universidade, permitindo que teoria e prática fomentem a troca e não a sobreposição de saberes.

Trata-se, sobretudo, de capacitar os acadêmicos para o domínio teórico-prático das linguagens artísticas no processo de alfabetização geográfica e, fundamentalmente, na formação para a cidadania, que no dizer das supervisoras, mas também dos ID, encontra-se na preparação e leituras, acesso a novas metodologias e tecnologias, contato com a Universidade e, fundamentalmente, formação diferenciada para todos os segmentos que participam do Programa.

As discussões e leituras, debates coletivos sobre vídeos e filmes, segundo pudemos constatar, sinalizam para possibilidades de compreensão das teorias da ciência geográfica e também didático-pedagógica. Veja-se que isso é objetivo do Projeto de Geografia, mas também do Programa PIBID.

Para por em prática (dentro e fora da sala de aula) as teorias que se busca compreender e o debate que se deseja construtivo, sobretudo para as supervisoras, que tiveram distanciamento da Universidade, após concluírem suas graduações, a participação no Programa proporciona sair da "acomodação" e pode interferir na prática. Esse é um dos objetivos pelo qual o PIBID foi criado e a percepção apresentada pelas professoras-supervisoras no decorrer dos debates e oportunidades de exposição.

Outro aspecto é que há a possibilidade de incorporação de novos meios para realização ensinoaprendizagem e isso também é objetivo do Programa. Nesse sentido, observa-se que o trabalho com diferentes metodologias e linguagens permite nova perspectiva sobre e para a Geografia, contribuindo, pela nossa avaliação, com a valorização da docência como instrumento criativo e, inclusive, como profissão, uma vez que estudantes da escola básica também começam a se ver como futuros professores e alguns dos ID do PIBID/Geografia se apresentam como alunos que vivenciaram a experiência do PIBID Geografia nas escolas básicas. 
Finalmente, se podemos dizer que avaliamos ainda que parcialmente, o impacto do PIBID/Geografia da UFGD, fica evidente que tem sido positivo. As oportunidades vivenciadas pelos acadêmicos, professores envolvidos e estudantes da escola básica, são, sem dúvida, diferenciais para suas vidas. Nesse sentido, vislumbramos, que a despeito das contradições que permeiam toda e qualquer política, o Programa, como instrumento formativo, tem nos levado a refletir sobre sua forma, se mostrado envolvente e poderia ser ampliado, mas, também, nos leva a refletir sobre a necessidade de pensarmos os estágios supervisionados obrigatórios, quem sabe sobre outras bases e com incentivos similares ao PIBID.

Aspectos que pretendemos nos aprofundar e acompanhar, reconhecendo, que enquanto política governamental, o PIBID está colocado em rota de colisão com os novos/velhos direcionamentos da política educacional brasileira, que tem, ao que parece, muito interesse em controlar o campo das ideias e dos discursos (re)elaborados no interior das escolas. Referimo-nos ao movimento (que já tem vários projetos de lei em discussão) "escola sem partido"; a Medida Provisória 746/2016, que cria o Novo Ensino Médio, ou ainda nos os muitos projetos de Lei em andamento no Congresso Nacional, que pretendem congelar salários, investimentos e acabar com o piso nacional do professor.

Nesse processo, o PIBID e seu movimento \#ficapibid tem se constituído em luta e resistência!

\section{REFERÊNCIAS}

ABREU, S. Uma análise da noção de espaço e sociedade do professor de Geografia do $1^{0}$ grau: formação, discurso e prática. Campo Grande: UFMS, Dissertação de mestrado, 1993. 181p.

ABREU, S. Formação de professor de Geografia: construindo conhecimento, consolidando práticas. Aspectos da relação ensino-aprendizagem In: ANDRES, J.,FRANCISCHERT, M. N.; AGUIAR, W. G. Ensino de Geografia: abordagens sobre representações geocartográficas e formação do professor. Cascavel/PR: EdUNOESTE, 2012, p.11-48.

ABREU, S. "O estágio supervisionado na formação dos professores de geografia: diálogos ininterruptos" In: ALBUquerque, M. A. M de \& FERREIRA J. A. de S. (org.). Formação, pesquisa e práticas docentes: reformas curriculares em questão. João Pessoa: Editora Mídia, 2013. p. 87-104.

ABREU, S.; SOUZA, A. O. Formação de Professores em Geografia/UFGD: o Programa Institucional de Bolsas de Iniciação à Docência In: XVI Encuentro Internacional Humboldt. São Carlos de Bariloche-ARG, 2014. (comunicação oral) 
AZEVEDO, J.W. 0 uso da sala de tecnologias educacionais no ensino de Geografia: desafios e perspectivas. Dourados (MS): UFGD (Dissertação), Mestrado em Geografia, 2009. 98p.

BRASIL. Lei no 9.394, 20 de dezembro de 1996. Estabelece as diretrizes e bases da educação nacional. Brasília/DF, 1996.

BRASIL. CAPES. Programa Institucional de Bolsas de Iniciação à Docência, 2008. Disponível em: http://www.capes.gov.br/educacao-basica/capespibid/pibid Acesso em 22/09/2016.

CARVAlHO, C.A.; CARVAlho FILHO, F.A. Ação integradora do PIBID nas escolas públicas de Viçosa. In: ANAIS. XVI Encontro Nacional de Geógrafos. Porto Alegre : AGB (Espaço de Diálogos e Práticas), 2010, 7p.

COVRE, M. L. A fala dos homens. Análise do pensamento tecnocrático (1964-1981). Rio de Janeiro: Brasiliense, 1983. 328 .

FUNDAÇÃO CARLOS CHAGAS. Um estudo avaliativo do Programa Institucional de Bolsa de Iniciação à Docência (PIBID). GATTI, B.A.; ANDRÉ, Marli, E.D.A.; GIMENEZ, N.A.S. e FERRAGUT, L. (Pesquisadores). São Paulo : FCC/SEP, 2014, 120p.

GATTI, B.A.; BARRETO, E.S.S. e ANDRÉ, M.E.A. Políticas recentes no Brasil - Um Estado da Arte. Brasília : UNESCO, setembro 2011, 300p.

GIROUX, H. Escola crítica e política cultural. São Paulo: Autores Associados, 1988. 104p

GRAMSCI, A. Os intelectuais e a organização da cultura. Rio de Janeiro : Civilização Brasileira, 1978.

MORAN, J. M. "O Uso das Novas Tecnologias da Informação e da Comunicação na EAD - uma leitura crítica dos meios". Palestra proferida no evento "Programa TV Escola - Capacitação de Gerentes", em 1999. In: http://portal.mec.gov.br/seed/arquivos/pdf/T6\%20TextoMoran.pdf . Acessado em 06/08/2015.

MUNIN, D. PIRES, G \& BENITES, L.. A contribuição do PIBID (Programa Institucional de Bolsas de Iniciação à Docência) na formação do professor de Geografia: a experiência da UFGD. In: ANAIS. XVI Encontro Nacional de Geógrafos. Porto Alegre : AGB (Espaço de Diálogos e Práticas), 2010, 6p.

NUNES, F. G. (Org.) Ensino de Geografia: Novos olhares e práticas. Dourados: Editora UFGD, 2011. 200p.

OLIVEIRA JR, W. M.; GIRARDI, G. Diferentes linguagens no ensino de Geografia Anais XI ENPEG, 2011.

OLIVEIRA, V.A.; PAZ LIMA, S.R. 0 papel do professor de Geografia no ensino médio: uma reflexão a partir do ensino público e do privado em Dourados. UFGD, Monografia, 2007. 67p.

PEREIRA, C.E.G.; SEEMANN, J. Representações cartográficas do espaço municipal: mapas artísticos em deriva da cartografia escolar Anais 3º Colóquio Internacional "Educação pelas imagens e suas geografias" Vitória (ES), 2013.

RUA, J. et al. Para ensinar Geografia. Rio de Janeiro : Access, 1993, 311p.

SOCZEK, D. PIBID como formação de professores: reflexões e considerações preliminares In: Formação Docente - Revista Brasileira de Pesquisa sobre Formação de Professores. ANPED. Autêntica Editora. V.03/nº 05 ago-dez, p.57-69, 2011. 
http://www.capes.gov.br/educacao-basica/capespibid . Acesso em 06/08/2015 e 22/09/2016.

http://www.capes.gov.br/educacao-basica/capespibid/editais-e-selecoes Acesso 21/09/2016

http://www.capes.gov.br/images/stories/download/bolsas/Projetos_Aprovados-PIBID_1Publicacao.pdf

Acesso

$21 / 09 / 2016$

www.facebook.com/groups/1600686786872263 Acesso 10/07/2016

http://www.observatoriodopne.org.br/metas-pne/15-formacao-professores Acesso 06/08/2015

www.pibid.ufv.br/wp-content/uploads/CARTA-FORPIBID.pdf Acesso em 10/07/2016

http://portal.mec.gov.br/. Acesso em 06/08/2015.

http://portal.mec.gov.br/index.php?option=com_docman\&view=download\&alias $=16762$-balanco-social-sesu-20032014\&category_slug=dezembro-2014-pdf\&Itemid=30192 Acesso em 19/09/2016. 